\title{
As novas formas de expressão do preconceito e do racismo ${ }^{1}$
}

\author{
Marcus Eugênio Oliveira Lima \\ Universidade Federal de Sergipe \\ Jorge Vala \\ Universidade de Lisboa
}

\begin{abstract}
Resumo
Recentemente tem-se verificado uma condenação social aberta às formas mais tradicionais e flagrantes de racismo. Em conseqüência, em várias partes do mundo, alguns estudos utilizando metodologias tradicionais de coleta de dados têm demonstrado que os estereótipos negativos associados aos negros têm diminuído. Todavia, novas e mais sofisticadas formas de expressão do preconceito e do racismo têm surgido, corporificando muitos comportamentos cotidianos de discriminação, quer ao nível institucional, quer ao nível interpessoal. Estas novas formas de expressão do preconceito e do racismo produzem na psicologia social várias teorizações. Temos as teorias do racismo moderno, do racismo simbólico, do racismo aversivo, do racismo ambivalente, do preconceito sutil e do racismo cordial, dentre outras. Neste trabalho procuramos analisar cada uma das novas teorias sobre o preconceito e sobre o racismo, e discorremos sobre o suporte empírico que fundamenta cada uma dessas teorias.
\end{abstract}

Palavras-chave: racismo; preconceito; negros; teorias

\begin{abstract}
The new forms of expression of prejudice and racism. Nowadays the democratic societies condemn the open and traditional forms of prejudice and racism. Consequently, some studies, using traditional data collection methodologies, have demonstrated that the negative stereotypes associated to the blacks are decreasing. However, new and more sophisticated forms of racism have emerged and produced many everyday discriminatory actions, at an institutional and interpersonal level. To analyze these new forms of expression of prejudice and racism several theories have emerged in social psychology. In this sense, we have the modern racism, symbolic racism, aversive racism, ambivalent racism, cordial racism and subtle prejudice theories. This work analyzes these new theories of racism and prejudice and describes some of their empirical support.
\end{abstract}

Keywords: racism; prejudice; blacks; theories

Mas, a partir do momento em que um homem precisou do auxílio de outro, a partir do momento em que se aperceberam ser útil a um só possuir provisões para dois, a igualdade desapareceu, a propriedade introduziu-se, o trabalho tornou-se necessário, e as vastas florestas transformaram-se em campos vicejantes que foi preciso regar com o suor dos homens, e nos quais logo se viu a escravidão e a miséria germinarem e crescerem com as colheitas. (J. J. Rousseau, 1755/1989, pp. 92-93) ${ }^{2}$

$\mathrm{P}$ oderíamos desenvolver esta linha de argumentação de Rousseau e acrescentar à escravidão e à miséria o surgimento do preconceito e do racismo. Com efeito, o preconceito e o racismo parecem ser tão antigos quanto são as relações assimétricas de poder entre os homens e a concomitante necessidade de justificação dessas relações.
Snowden (1995), numa análise histórica do preconceito, afirma que já existia preconceito na antiguidade greco-romana, embora este não fosse um preconceito de base racial, uma vez que não existiam divisões e hierarquias raciais naquela época; mas sim um preconceito de base cultural: existia um preconceito contra os escravos, que na maior parte das vezes eram brancos (Snowden, 1983, 1995).

Contudo, desde a antiguidade greco-romana até os dias atuais as sociedades avançaram muito em termos de direitos humanos e de estratégias de resolução dos conflitos intergrupais. De modo que poderíamos pensar que o preconceito está em vias de se resolver. A realidade dos fatos, infelizmente, nega esta expectativa. Não obstante tenhamos assistido, já no século XX, a um importante conjunto de mudanças sociais e políticas ocorridas nas décadas de 40 e de 
50, como por exemplo, a crítica ao regime nazi-fascista, a Declaração dos Direitos Humanos (1948), a condenação da UNESCO às classificações raciais (1950), as lutas pelos direitos civis nos EUA e vários movimentos sociais importantes na Europa. Apesar de todos estes importantes acontecimentos, o preconceito e o racismo permanecem um problema grave e atual.

No entanto, apesar da sua relevância enquanto problema social, o preconceito e o racismo quase sempre foram percebidos como sendo um problema do outro e, portanto, distante de cada um de nós. Seja porque nós, enquanto atores sociais e imbuídos dos valores do igualitarismo e da justiça que compõem a nossa formação democrática, analisamos o racismo na maior parte das vezes como um problema do outro "xenófobo". Seja ainda porque as vítimas de preconceito são quase sempre outros que não nós mesmos. Com efeito, segundo uma pesquisa realizada junto a uma amostra representativa dos países da comunidade européia em 1997, apenas $22 \%$ dos europeus estão preocupados com o racismo nos seus países (Ben Brika, Lemaine, \& Jackson, 1997). No Brasil, uma pesquisa realizada junto a uma amostra representativa da população nacional indicou que quase $90 \%$ dos entrevistados se considera não racista, ao mesmo tempo em que igual percentagem de brasileiros acredita que existe racismo no Brasil (Turra \& Venturi, 1995). Schwarcz (1996) e Camino, Silva, Machado e Pereira (2001) encontram resultados semelhantes em amostras de estudantes universitários.

Estas percepções sociais do preconceito e do racismo parecem ser importantes em sociedades nas quais os partidos nacionalistas, com flagrante discurso racista e xenófobo, proliferam e se tornam progressivamente mais poderosos como no caso de alguns países da Europa (e.g., França, Áustria, Holanda e Itália), ou ainda em países nos quais a população negra discriminada é a maior do mundo vivendo fora da África, como é o caso do Brasil.

Este trabalho tem por objetivo analisar as novas formas de expressão do preconceito e do racismo, que se manifestam em sociedades formalmente democráticas. Para tanto, primeiramente definimos e diferenciamos preconceito e racismo. Em seguida abordarmos as chamadas "novas expressões" de preconceito e de racismo. Especificamente analisamos os racismos moderno e simbólico da Austrália e dos EUA; os racismos aversivo e ambivalente dos EUA, o preconceito sutil da Europa e, finalmente, o racismo cordial do Brasil.

\section{Preconceito e racismo: breve panorama conceitual}

Foi Gordon Allport (1954), num trabalho seminal sobre o preconceito, quem traçou as linhas fundamentais que definem as principais perspectivas de análise do preconceito na atualidade. Para Allport, o preconceito pode ser definido como uma atitude hostil contra um indivíduo, simplesmente porque ele pertence a um grupo desvalorizado socialmente (Allport, 1954). ${ }^{3}$

De acordo com esta definição, e pelo fato de existirem vários grupos socialmente desvalorizados, temos tantos tipos de preconceito quantas pertenças a grupos minoritários na estrutura de poder (e.g., preconceito contra as mulheres ou sexismo, preconceito contra os homossexuais ou homofobia, preconceito contra os velhos ou ageísmo, preconceito contra pessoas gordas, preconceito contra pessoas com deficiências físicas e/ou mentais, preconceito contra os nordestinos no Brasil ou contra os alentejanos em Portugal, etc.). Dentre as várias formas possíveis de preconceito existe uma peculiar, que se dirige a grupos definidos em função de características físicas ou fenotípicas supostamente herdadas: trata-se do preconceito racial ou, para alguns autores, preconceito étnico (e.g., Allport, 1954; Stephan, 1985).

Allport (1954) define o preconceito étnico como uma antipatia baseada numa generalização falha e inflexível, que pode ser sentida ou expressa e que pode ser dirigida a um grupo como um todo ou a um indivíduo porque ele faz parte daquele grupo. ${ }^{4}$

O racismo, por sua vez, diferentemente do preconceito, é muito mais do que uma atitude. O racismo constitui-se num processo de hierarquização, exclusão e discriminação contra um indivíduo ou toda uma categoria social que é definida como diferente com base em alguma marca física externa (real ou imaginada), a qual é re-significada em termos de uma marca cultural interna que define padrões de comportamento. Por exemplo, a cor da pele sendo negra (marca física externa) pode implicar na percepção do sujeito (indivíduo ou grupo) como preguiçoso, agressivo e alegre (marca cultural interna). É neste sentido que, como afirma Guimarães (1999), o racismo é uma redução do cultural ao biológico, uma tentativa de fazer o primeiro depender do segundo.

Neste sentido, o racismo pode ser distinguido do preconceito por uma série de características. O racismo repousa sobre uma crença na distinção natural entre os grupos, ou melhor, envolve uma crença naturalizadora das diferenças entre os grupos, pois se liga à idéia de que os grupos são diferentes porque possuem elementos essenciais que os fazem diferentes, ao passo que o preconceito não implica na essencialização ou naturalização das diferenças. Outra diferença entre racismo e preconceito é de que o racismo, diferentemente do preconceito, não existe apenas a um nível individual, mas também a nível institucional e cultural (Jones, 1972). Isto é uma conseqüência do fato de o racismo englobar os processos de discriminação e de exclusão social, enquanto que o preconceito permanece normalmente como uma atitude.

Tendo definido e diferenciado o racismo do preconceito, podemos agora analisar as novas formas de expressão destes dois fenômenos das relações intergrupais.

\section{As novas formas de expressão do preconceito e do racismo}

Defeated intellectually, prejudice lingers emotionally. ${ }^{5}$ (Allport, 1954, p.328)

Seguindo a elucidativa contextualização histórica do racismo proposta por Duckitt (1992), podemos afirmar que as definições e os níveis de análise do preconceito e do racismo refletem os ambientes sociais e históricos onde acontecem as relações racializadas ${ }^{6}$ de tal maneira que a natureza e as for- 
mas de expressão do preconceito são influenciadas, e mesmo definidas, pelas normas sociais que estejam salientes no contexto (Allport, 1954; Correia, Brito, Vala, \& Pérez, 2001; Dovidio, 2001; Gaertner \& Dovidio, 1986; Lima \& Vala, 2002; Pettigrew, 1958, 1959/1993).

Nos séculos de exploração do trabalho escravo dos negros e de colonização dos índios o racismo era expresso de maneira aberta, pois refletia as normas sociais da época: as normas da discriminação e da exploração. Depois da $2^{\underline{a}}$ Guerra Mundial ocorreram mudanças históricas significativas, tais como: a emergência dos movimentos pelos direitos civis nos EUA, os movimentos de libertação de antigas colônias européias, as conseqüências do nazismo e a Declaração dos Direitos Humanos.

A partir deste momento as formas de expressão do racismo e do preconceito mudaram tão significativamente que se poderia pensar que estes fenômenos estavam em extinção. Com efeito, uma série de pesquisas utilizando metodologias tradicionais de coleta de dados ou medidas diretas de atitudes raciais, feitas em épocas diferentes, demonstraram que as atitudes contra os Negros, em vários lugares do mundo, estavam mudando drasticamente.

Nos EUA os estereótipos atribuídos aos negros pelos americanos brancos tornaram-se progressivamente menos negativos. Nos anos 30 mais de $80 \%$ dos americanos brancos consideravam os negros como supersticiosos. Esta aceitação aberta do estereótipo negativo cai para 3\% nos anos 90 (ver Tabela 1).

Tabela 1

Mudanças históricas nos estereótipos dos americanos brancos em relação aos negros (amostras de estudantes universitários, em porcentagem)

\begin{tabular}{lccc}
\hline Estereótipos dos negros & 1933 & 1967 & 1990 \\
\hline Supersticiosos & 84 & 13 & 3 \\
Preguiçosos & 75 & 26 & 4 \\
Ignorantes & 38 & 11 & 5 \\
Estúpidos & 22 & 4 & 3 \\
Fisicamente sujos & 17 & 3 & 0 \\
Não confiáveis & 12 & 6 & 4 \\
\hline
\end{tabular}

Fonte: Brown (1995, p. 209)

Na Europa, em uma pesquisa realizada junto a amostras representativas de vários países, $70 \%$ dos europeus afirmam que os imigrantes devem ter os mesmos direitos que os europeus (Ben Brika et al., 1997).

No Brasil, dados comparativos dos estereótipos atribuídos aos negros na década de 50 e no ano de 2001, em amostras de estudantes universitários brancos, indicam também um claro padrão de mudança nos estereótipos associados aos negros. Como podemos ver na Tabela 2, os estereótipos negativos em relação aos negros praticamente caíram em desuso, à exceção de supersticiosos. Em contrapartida, os dados indicam que os estereótipos positivos ganharam mais poder com o tempo.
Tabela 2

Mudanças históricas nos estereótipos dos brasileiros brancos em relação aos negros (amostras de estudantes universitários, em porcentagem)

\begin{tabular}{lcc}
\hline Estereótipos dos negros & 1950 & 2001 \\
\hline Supersticiosos & 80 & 52 \\
Preguiçosos & 62 & 5 \\
Estúpidos & 43 & 8 \\
Musicais & 22 & 80 \\
Atléticos ou fortes & 45 & 65 \\
Alegres & 46 & 85 \\
\hline
\end{tabular}

Fonte: os dados da década de 1950 resultam de dois estudos (Bastide \& Van den Berghe, 1957; Cardoso \& Ianni, 1959). Os dados de 2001 são de M. E. O. Lima (Comunicação pessoal, 2001).

Todos esses dados parecem indicar que o preconceito contra grupos minoritários está em declínio na atualidade. Todavia, uma análise mais cuidadosa desses mesmos dados e de outros apresenta um quadro bem diferente e muito menos colorido. Com efeito, outras pesquisas revelam que estamos muito longe da igualdade social. Nos EUA, por exemplo, não obstante possa ser verdade que alguns grupos menos privilegiados avançaram em áreas como educação, emprego, e moradia; uma análise mais aproximada revela que, em termos relativos, as desigualdades permanecem e mesmo aumentaram em alguns aspectos (Dovidio \& Gaertner 1998; Pettigrew, 1985).

Na Europa, os mesmos dados do Eurobarômetro de 1997, que indicavam que $70 \%$ dos europeus achavam que os imigrantes deveriam ter direitos iguais aos europeus, indicam que apenas $55 \%$ concordam que eles (os imigrantes) devam ter consigo suas famílias, $59 \%$ consideram que as minorias de outras raças, religiões, ou culturas, abusam do sistema de segurança social, $63 \%$ acham que eles contribuem para aumentar o desemprego e mais de $45 \%$ acham que eles são a causa da insegurança (Ben Brika et al., 1997).

No Brasil, uma análise cuidadosa das características positivas atribuídas aos negros indica uma nova e mais sofisticada forma de preconceito, uma vez que os estereótipos positivos aplicados definem claramente papéis sociais específicos para este grupo. Podemos pensar que se eles são musicais, são também aptos para o ritmo e para a dança, se são fortes, estão aptos para o trabalho braçal, e se são alegres, não devemos nos preocupar com a sua situação social, pois nem eles têm consciência dela (ver Allport, 1954; Amâncio, 1998; Jost \& Banaji, 1994; Tajfel, 1981, para uma revisão sobre o papel justificador dos estereótipos).

Os resultados das tabelas apresentadas e de vários outros estudos feitos sobre preconceito e racismo pós $2^{\text {a }}$ Guerra Mundial indicam invariavelmente uma mudança nas suas formas de expressão. As pessoas, face às pressões da legislação anti-racista e dos princípios da igualdade e da liberdade apregoados pelas democracias liberais, começaram a expressar seu preconceito de uma forma mais sutil e velada. É nesse quadro que se começa a falar de "Novos Racismos" ou de "Novos Preconceitos". 
Estas novas expressões do preconceito recebem diversos nomes e apresentam peculiaridades próprias aos seus contextos de imersão. E é neste sentido que outros autores vão falar em retorno do racismo (Pereira, 1996).

É importante referir que essas novas expressões de racismo se colocam como um contraponto em relação às expressões tradicionais ou clássicas de racismo; estas típicas dos séculos passados e mais abertas e flagrantes. Embora menos freqüentes (Dovidio \& Gaertner, 1998), as expressões mais flagrantes de racismo ainda existem e com conseqüências institucionais nefastas para os grupos estigmatizados. Como argumenta Essed (1991), as novas formas de preconceito e racismo, por sua vez, situam-se, sobretudo, ao nível das relações interpessoais e referem-se a comportamentos discriminatórios da vida cotidiana das pessoas.

Assim, temos o racismo moderno na Austrália e nos EUA (McConahay \& Hough, 1976; Pedersen \& Walker, 1997), o racismo simbólico nos EUA (Kinder \& Sears, 1981), o racismo aversivo também nos EUA (Gaertner \& Dovidio, 1986), o racismo ambivalente nos EUA (Katz \& Hass, 1988), o racismo sutil na Europa (Pettigrew \& Meertens, 1995) e o racismo cordial no Brasil (Turra \& Venturi, 1995).

\section{Racismo simbólico e racismo moderno}

Estas duas formas de racismo possuem muitos elementos comuns e por isso costumam ser consideradas conjuntamente (Biernat, Vescio, Theno, \& Crandall, 1996; Walker, 2001). A primeira conceituação de "novos racismos" data dos anos 1970 e surge por meio do conceito de racismo simbólico (Sears \& Kinder, 1971; Sears \& McConahay, 1973). ${ }^{7}$ O racismo simbólico representa uma forma de resistência a mudanças no status quo das relações racializadas nos EUA pós Declaração dos Direitos Civis. Esta forma de racismo se baseia em sentimentos e crenças de que os negros violam os valores tradicionais americanos do individualismo ou da ética protestante (obediência, ética do trabalho, disciplina e sucesso) (Kinder \& Sears, 1981).

Nesta perspectiva as atitudes contra os negros decorrem menos da percepção por parte do grupo dominante de que os negros constituem uma ameaça econômica concreta, e mais da percepção dos negros como uma ameaça simbólica, ameaça aos valores e à cultura do grupo dominante. Os negros são percebidos como violadores dos valores que mantêm o status quo das relações inter-raciais.

Kinder e Sears (1981) realizam um estudo para confirmar estas asserções e verificam que o racismo simbólico está associado à crença de que os negros estão indo muito longe na luta por direitos iguais e com o desejo de restrição das políticas de ação afirmativa. Isto ocorreria tanto para os simpatizantes do partido conservador quanto para os simpatizantes do partido liberal (Sears, 1998).

O termo racismo simbólico foi escolhido porque, segundo os autores, alguns itens da escala utilizada pressupunham abstração moral e enfatizavam sentimentos e crenças adquiridas ao longo da socialização e não através da competição direta com os negros (Sears \& Kinder, 1971).
A teoria do racismo moderno, por sua vez, surge de uma necessidade empírica: medir as atitudes raciais públicas dos indivíduos, quando as normas sociais inibem as expressões abertas de racismo. Assim, esta teoria foi desenvolvida em simultâneo com a Escala de Racismo Moderno (McConahay \& Hough, 1976). O conceito de racismo moderno, assim como o do racismo simbólico, reflete a percepção de que os negros estão recebendo mais do que merecem e violando valores importantes para os brancos.

Os valores importantes em questão são a igualdade e a liberdade, valores típicos do American Creed ${ }^{8}$ (ver Myrdal, 1944). Cabe referir, ainda seguindo McConahay (1986), que a percepção de que os negros violam o valor da igualdade se refere a algo específico do credo americano, "os americanos acreditam na igualdade de oportunidades, mas não na igualdade de benefícios" (McConahay, 1986, p. 99).

Assim, de uma maneira sintética, o racismo moderno se baseia no seguinte conjunto de crenças e avaliações: a) a discriminação é uma coisa do passado porque os negros podem agora competir e adquirirem as coisas que eles almejam; b) os negros estão subindo economicamente muito rápido e em setores nos quais não são bem-vindos; c) os meios e as demandas dos negros são inadequados ou injustos e, d) os ganhos recentes dos negros não são merecidos e as instituições sociais lhes dão mais atenção do que eles deveriam receber (McConahay, 1986). Com efeito, a maior parte dos itens da escala de racismo moderno enfoca estas questões (e.g., "Over the past few years, the government and news media have shown more respect for blacks than they deserve", ou "Blacks are getting too demanding in their push for equal right", McConahay, 1986, p. 104).

O racismo moderno também foi pesquisado em outros contextos além do norte-americano, e utilizando outro tipo de alvo além dos negros. Pedersen e Walker (1997) realizaram um estudo sobre o preconceito contra os aborígenes na Austrália, cujo objetivo foi verificar a relação entre o racismo moderno e o racismo flagrante (old-fashioned). Para esse efeito, os autores utilizaram uma adaptação da escala de racismo moderno proposta por Augoustinos, Ahrens e Innes (1994) e uma escala de racismo flagrante contra os aborígenes proposta por Walker (1994). Os resultados indicam primeiramente que as duas dimensões investigadas de racismo (moderno e flagrante) se mostram positivamente correlacionadas e ao mesmo tempo diferenciadas. $\mathrm{O}$ racismo moderno é maior ou mais expressivo na amostra do que o racismo flagrante. Além disto, o autoritarismo de extrema direita e o sentimento de privação relativa grupal apresentam-se mais fortemente relacionados com o racismo moderno do que com o racismo flagrante.

\section{Racismo aversivo}

Assim como as teorias do racismo simbólico e do racismo moderno, Gaertner e Dovidio (1986) distinguem entre duas formas de racismo. Estes autores, inspirando-se numa análise das relações raciais americanas, feita por Joel Kovel na década de 70, afirmam que existem os racistas dominantes (ou flagrantes), raros hoje em dia, e que existem aqueles indi- 
víduos que se distinguem pela força com que adotam os valores do igualitarismo e tentam se auto-apresentarem como pessoas igualitárias e sem preconceito racial; estes são os racistas aversivos, os que têm, ou melhor, parecem ter, aversão ao racismo.

A teoria do racismo aversivo, assim como as anteriores, parte da pressuposição encontrada no dilema americano de Myrdal (1944), que afirma que a natureza fundamental das atitudes dos americanos brancos para com os negros não é nem uniformemente negativa nem totalmente favorável, mas ambivalente, pois reflete em simultâneo a crença de que a sociedade norte-americana é democrática e cristã, definida pelo autor como "credo americano", e o fato de os negros serem violentamente discriminados e segregados nesta sociedade. Para Kovel (1970/2001), autor que, numa análise psicanalítica do racismo nos EUA, cria o conceito de racismo aversivo, o grande problema da sociedade americana era o de, depois da conquista dos direitos civis, incluir os negros na equação da democracia. Um problema já naquela época não resolvido. ${ }^{9}$

Para Gaertner e Dovidio (1986) o racismo aversivo seria o tipo de atitude racial que caracterizaria muitos americanos brancos que possuem fortes valores igualitários, mas que experienciam um tipo particular de ambivalência, resultante do conflito entre sentimentos e crenças associados a valores igualitários e sentimentos negativos face aos negros.

Em termos de etiologia o racismo aversivo é concebido como uma síntese decorrente, por um lado, da assimilação de um sistema de valores igualitários e, por outro lado, da vivência de sentimentos e crenças negativos em relação aos negros. Estes sentimentos e crenças negativos, de acordo com a teoria, seriam uma decorrência de dois mecanismos: a) do contexto racista de socialização a que os atores sociais estão sujeitos, e b) dos mecanismos da categorização e do viés endogrupal, que contribuem para o desenvolvimento dos estereótipos e do preconceito.

Os sentimentos negativos em relação aos negros que caracterizam a ambivalência, nos racistas aversivos não são sentimentos de hostilidade ou ódio, mas de desconforto, nervosismo, ansiedade e algumas vezes medo das pessoas negras. Estes sentimentos ou melhor dizendo, estas emoções, motivam mais a evitação do contato próximo do que comportamentos destrutivos e violentos (Dovidio \& Gaertner, 1998; Gaertner \& Dovidio, 1986).

Os pressupostos empíricos da teoria do racismo aversivo derivam da hipótese de que quando as pessoas são defrontadas com situações de contato inter-racial nas quais a resposta apropriada é clara, em que o certo e o errado estão claramente definidos, os racistas aversivos não discriminam os negros, pelo contrário, eles endossam tratamento igualitário para negros e brancos. Entretanto, quando a norma igualitária não está explícita na situação ou existe um contexto que justifica a discriminação, os racistas aversivos discriminam os negros (Dovidio \& Gaertner, 1998).

Para testar estes pressupostos, os autores conduziram uma série de estudos utilizando o paradigma do comportamento de ajuda e observaram que indivíduos brancos, de maneira geral, socorriam mais uma vítima negra (95\% das vezes) do que uma vítima branca (83\%). Entretanto, quando os participantes possuíam uma oportunidade para justificar o seu racismo, ou seja, quando os participantes eram levados a acreditar que outras pessoas assistiam a cena e que poderiam também socorrer a vítima, a vítima negra era menos socorrida (38\%) do que a branca (75\%) (Gaertner \& Dovidio, 1986).

$\mathrm{O}$ estudo original que inspirou esta teoria foi realizado, no entanto, ainda na década de 1970, por Samuel Gaertner (1973). Ele criou uma situação, utilizando o paradigma do comportamento de ajuda, na qual um cúmplice do pesquisador, branco ou negro (a "raça" era identificável pelo sotaque), telefonava para simpatizantes do partido Liberal e do partido Conservador, e explicava que seu carro havia quebrado em um lugar distante e que ele estava tentando chamar o serviço de uma oficina, por meio de um telefone público, mas que fizera a ligação errada. Entretanto, como não tinha mais como fazer outra chamada, pedia ao indivíduo que atendera ao telefone para ajudá-lo, avisando a oficina onde ele e seu carro se encontravam. $\mathrm{O}$ indicador de racismo utilizado foi o comportamento de ajuda, analisado em termos do comportamento de telefonar para a suposta oficina, onde outro cúmplice do pesquisador atendia ao telefonema.

Os resultados indicaram que os simpatizantes do partido Conservador prestaram menos ajuda aos negros do que aos brancos (65\% vs. 92\%), que os simpatizantes do partido Liberal ajudaram negros e brancos de uma maneira não diferenciada (75\% vs. $85 \%$, respectivamente), que os "liberais" desligavam o telefone de maneira prematura mais freqüentemente para os negros do que para os brancos (19\% vs. $3 \%)$, e que os "conservadores" não discriminam desta maneira ( $8 \%$ vs. $5 \%$ ).

Todavia, enquanto o estudo estava em progresso, outros simpatizantes dos partidos Liberal e Conservador eram entrevistados sobre o que eles acreditavam que fariam se recebessem uma chamada telefônica errada de um motorista negro ou branco. Os simpatizantes desses partidos indicaram que ajudariam e que fariam isso sem considerar a raça da pessoa. Gaertner conclui afirmando que quando as normas para comportamentos apropriados estão bem-definidas, sujeitos brancos não discriminam contra negros; quando as normas são ambíguas ou conflitantes, tornando o conceito de certo e errado menos aplicável, aí sim surge o racismo aversivo.

Dovidio e Gaertner (2000), num estudo mais recente, analisam o racismo aversivo num contexto de seleção de candidatos a um emprego. Os participantes deste estudo, americanos brancos, foram solicitados a avaliarem eventuais candidatos a um emprego com base em extratos de uma entrevista. Foram utilizados três resultados das entrevistas, um primeiro que refletia altas qualificações (o pré-teste indicou que o candidato seria aceito em $85 \%$ dos casos), um segundo que representava fracas qualificações (o candidato seria aceito em $15 \%$ dos casos no pré-teste) e um terceiro envolvendo qualificações moderadas (o candidato seria aceito em $50 \%$ dos casos). Os participantes avaliaram a um único candidato, descrito como branco ou como negro. De acordo com os pressupostos do racismo aversivo, a hipótese principal dos autores 
era a de que a discriminação contra o candidato negro seria expressa apenas no contexto em que houvesse justificação para isto, ou seja, no contexto de qualificação moderada. De fato, os resultados indicaram que na condição ambígua, quando os resultados dos candidatos eram moderados, os participantes recomendaram o candidato negro menos (45\%) do que o candidato branco $(76 \%)$. Nas outras condições não houve diferenças significativas nas recomendações de contratação para o candidato branco e para o candidato negro.

\section{Racismo ambivalente}

A ambivalência de sentimentos e atitudes é uma característica fundamental das interações sociais e os seus efeitos têm consequiências sobre as mais variadas esferas da vida social (ver Conner \& Sparks, 2002, para uma revisão). No campo das atitudes raciais existe uma teoria específica que trata dos efeitos da ambivalência de sentimentos na expressão do racismo, a teoria do racismo ambivalente.

A título de ilustração dos efeitos da ambivalência no racismo, podemos referir um desses muitos exemplos de expressão do preconceito com que nos confrontamos na vida quotidiana. Um dia, num programa infantil na TV, vimos uma cena na qual uma apresentadora branca colocava no colo crianças do auditório. Ela pegava a criança, fazia um ligeiro afago, e em seguida entregava para uma das suas assistentes. Ela fez isto com seis ou sete crianças brancas uma após a outra; a criança seguinte era uma menina negra. A apresentadora mudou todo o seu esquema gestual, além do afago beijou repetidamente a criança, antes de entregá-la para a sua assistente. Este comportamento é típico de uma nova forma de racismo, ou melhor dizendo, de um elemento ubíquo a todas as "novas formas" de racismo, a ambivalência.

Katz, Wackenhut e Hass (1986) afirmam que a ambivalência é a característica mais saliente nas relações raciais dos norte-americanos brancos. Estes autores, considerando que os valores determinam as atitudes e os comportamentos, analisam um suposto conflito entre duas orientações axiológicas dos norte-americanos. Por um lado, existe uma valorização da democracia e do igualitarismo e por outro também é importante o individualismo, caracterizado pela ênfase na liberdade pessoal, na autoconfiança, na devoção ao trabalho, e na realização. Estas duas orientações podem produzir um conflito e gerar ambivalência de sentimentos e atitudes dentro dos indivíduos. Assim, ao aderir aos valores da igualdade e do humanitarismo os brancos podem sentir simpatia pelos negros, que estão em pior situação social e econômica. Esta simpatia pode gerar ações em prol desse grupo. Por outro lado, a adesão aos valores do individualismo, típicos da ética protestante, levaria os brancos a identificarem os negros como sendo desviantes em relação a estes valores. Esta percepção estaria na origem de sentimentos de aversão e de atitudes negativas em face aos negros.

Portanto, a ambivalência resulta da dupla percepção de que os negros são desviantes e, ao mesmo tempo, estão em desvantagem em relação aos brancos. A ambivalência de sentimentos e atitudes normalmente gera uma tensão e um desconforto psicológicos. Para reduzir esta tensão e este des- conforto os indivíduos tenderiam a polarizar ou radicalizar suas atitudes raciais. Este fenômeno de exagero das repostas, conhecido como response amplification (Bell \& Esses, 2002; Jonas, Broemer, \& Diehl, 2000), está bem ilustrado no nosso exemplo da apresentadora de programa infantil.

Para Katz e Hass (1988) a ambivalência estrutura dois tipos de atitudes, as atitudes pró e as atitudes anti-negros. As atitudes anti-negros incluem crenças e avaliações sobre as características de "desvio cultural" e associam aos negros afetos negativos. As atitudes pró-negros refletem a percepção de desvantagem dos negros e produzem afetos positivos, tais como piedade ${ }^{10}$ e simpatia.

A principal hipótese que resulta destas afirmações é a de que quanto maior a saliência dos valores do individualismo, maior a emergência dos sentimentos negativos e, portanto, maior a discriminação contra os negros; por outro lado, quanto maior a saliência dos valores do igualitarismo, maior a emergência dos sentimentos positivos e menor a discriminação contra os negros.

Estas hipóteses recebem algum suporte empírico. Katz e Hass (1988, estudo 1) encontram uma correlação positiva entre a adesão aos valores da ética protestante e as atitudes antinegros, e uma correlação também positiva entre a adesão aos valores do igualitarismo/humanitarismo e as atitudes pró-negros. Num segundo estudo, Katz e Hass (1988) analisam os efeitos das escalas de Ética Protestante e de Igualitarismo, manipuladas enquanto contextos ou estímulos de resposta priming $^{11}$ - sobre as atitudes pró e anti-negros. Os autores verificam que o grupo de participantes brancos que respondeu à escala de Ética Protestante (condição individualista) apresenta mais atitudes anti-negros do que o grupo que respondeu a uma escala neutra sobre efeitos da alimentação na saúde (condição controle). Entretanto, o grupo que respondeu à escala de Igualitarismo/Humanitarismo (condição igualitária) não se diferenciou da condição controle nas atitudes pró-negros.

A teoria do racismo ambivalente se assemelha em muitos pressupostos à teoria do racismo aversivo. Tanto o racista ambivalente quanto o racista aversivo procuram manter uma auto-imagem e imagem pública de pessoa igualitária e não preconceituosa. Em ambas as perspectivas, a noção de conflito ou de ambivalência está colocada num nível intrapsíquico e a resolução deste conflito é entendida como sendo primordialmente não-consciente (Walker, 2001).

\section{Preconceito sutil}

As quatro formas de racismo já analisadas refletem aspectos particulares da realidade inter-racial norte-americana e, portanto, caracterizam-se pela discriminação de um grupo de pessoas que são nativas do país onde as pesquisas são realizadas (os negros nos EUA e os aborígenes na Austrália). O preconceito sutil é uma teoria que surge para explicar outra nova expressão do preconceito, o preconceito contra grupos exógenos ou externos.

O preconceito sutil é estudado na Europa e tem como grupo alvo minorias culturais advindas de antigas ex-colônias de países europeus. Esta forma de preconceito ganha em 
dimensão na medida em que a globalização das economias intensifica os contatos interétnicos e os fluxos migratórios.

Pettigrew e Meertens (1995), seguindo Allport (1954), distinguem entre preconceito flagrante (blatant) e preconceito sutil (subtle). O preconceito flagrante é definido como mais direto, aberto e "quente"12, ao passo que o preconceito sutil é "frio", distante e indireto". Para Pettigrew e Meertens existiriam duas dimensões no preconceito flagrante: 1) a dimensão da ameaça e rejeição do exogrupo, que se baseia na percepção de que os membros do exogrupo constituem uma ameaça, sobretudo econômica, e que portanto devem ser rejeitados (e.g., "Os ' $\mathrm{X}$ ' têm empregos que deveriam pertencer aos nacionais"); e 2) a dimensão da rejeição da intimidade, definida como uma rejeição emocional ao contato íntimo, concretamente o contato sexual e o casamento (e.g., "Importavame que um familiar meu se casasse com um ' $\mathrm{X}$ ' de meio social semelhante") (Pettigrew \& Meertens, 1995, p. 62).

O preconceito sutil, uma forma mais velada ou disfarçada de preconceito, é composto por três dimensões. A primeira dimensão é a dimensão da defesa dos valores tradicionais. Esta dimensão se refere à percepção dos membros do exogrupo como estando agindo de maneira incorreta e mesmo condenável na busca da realização social: "Outgroup members are seen to act in unacceptable ways, in not to perform in ways necessary to succeed" (Pettigrew \& Meertens, 1995, p. 58). Esta dimensão é mensurada por meio de questões referentes à crença de que os membros do exogrupo não se esforçam o suficiente ou não possuem os valores adequados (e.g., "Algumas pessoas não se esforçam o suficiente, se os ' $\mathrm{X}$ ' se esforçassem mais eles poderiam ser tão bem sucedidos quanto os nacionais"). A segunda dimensão é a dimensão do exagero das diferenças culturais, que se refere à percepção de que o exogrupo é culturalmente muito diferente do endogrupo (e.g., "Os ' $\mathrm{X}$ ' possuem valores e comportamentos sexuais muito diferentes dos cidadãos nacionais”). Finalmente, a terceira dimensão do preconceito sutil, a dimensão da negação de emoções positivas, caracteriza-se pela rejeição à expressão de simpatia e admiração com relação aos membros do exogrupo (e.g., "Com que frequência sente admiração pelos 'X'”) (ver Pettigrew \& Meertens, 1995, p. 62).

A fim de testarem este modelo teórico, Pettigrew e Meertens (1995) procederam a uma análise dos dados do Eurobarômetro $^{14}$ de 1988. As amostras pesquisadas foram representativas de quatro países europeus e referentes a grupos de imigrantes importantes nesses países: na Inglaterra (indianos e asiáticos), na França (norte-africanos e asiáticos), na Alemanha Ocidental (turcos) e na Holanda (surinameses e turcos). Tomando como base os escores obtidos pelos respondentes nas duas escalas, esses mesmos autores criam três grupos de análise: os "flagrantes" (altos escores na escala sutil e na escala flagrante), os "sutis" (altos escores na escala sutil e baixos escores na escala flagrante) e os "igualitários" (baixos escores nas duas escalas). Os autores verificam que estes três grupos apresentam padrões de respostas muito diferenciados no que concerne às políticas de imigração e à percepção dos direitos dos imigrantes. Os igualitários são favoráveis à ampliação dos direitos dos imigrantes; os flagrantes preferem restringir os direitos já existentes e até fazer voltar os imigrantes para os seus países de origem; enquanto que os sutis não querem nem alargar nem diminuir os direitos das minorias, preferem manter o status quo das relações interétnicas (Pettigrew \& Meertens, 1995).

\section{Racismo cordial}

As teorias sobre as novas expressões de racismo apresentadas até então resultam de estudos realizados em sociedades definidas como "bi-raciais", nas quais a definição entre as diferenças se faz pela simples percepção de grupos exógenos, como no caso da Europa; ou por meio de uma explícita e institucionalmente definida "marca interna" de diferenciação, com base na ascendência "racial", como no caso dos EUA. Mas, como se expressa o racismo numa sociedade em que o universo de cores da pele catalogadas supera a uma centena? ${ }^{15} \mathrm{E}$ onde o contato inter-racial, mais do que uma contingência, foi sempre um fenômeno definidor da identidade social da população (ver Degler, 1971, Skidmore, 1993, para comparações entre o racismo em sociedades "bi-raciais" e em sociedades "multirraciais").

Estes elementos, associados a outras questões históricas e culturais, dentre as quais se destacam o mito da democracia racial e a ideologia do branqueamento (ver Guimarães, 1999; Schwartz, 1993, 1996, para revisões teóricas), fazem surgir no Brasil uma forma específica de expressão do racismo, o racismo cordial.

Turra e Venturi (1995), estudando as relações inter-raciais, analisam um tipo de racismo tipicamente brasileiro de "racismo cordial". O racismo cordial é definido como uma forma de discriminação contra os cidadãos não brancos (negros e mulatos), que se caracteriza por uma polidez superficial que reveste atitudes e comportamentos discriminatórios, que se expressam ao nível das relações interpessoais através de piadas, ditos populares e brincadeiras de cunho "racial". O pressuposto empírico desta teoria resulta de um estudo realizado junto a uma amostra representativa da população brasileira no qual se verificou que, apesar de $89 \%$ da amostra afirmar que existe racismo no Brasil, apenas $10 \%$ admitem ser racistas. Turra e Venturi (1995) utilizaram então uma escala menos direta com 12 itens (e.g., "Negro bom é negro de alma branca", "Negro, quando não faz besteira na entrada, faz na saída", etc.), e verificaram que mais de $50 \%$ da amostra pesquisada concorda com afirmativas deste tipo. De uma maneira geral, $83 \%$ da população entrevistada concorda, em algum nível, com os itens da escala de racismo cordial.

Como afirma Guimarães (1999, p. 67), numa obra importante em que analisa o racismo e o anti-racismo no Brasil: "trata-se de um racismo sem intenção, às vezes de brincadeira, mas sempre com conseqüências sobre os direitos e as oportunidades de vida dos atingidos". Não obstante essa aparente falta de intenção e sutileza de expressão, o racismo à brasileira nada tem de cordial, pois implica num cenário sinistro de discriminação e exclusão das pessoas negras, como indicam os dados amplamente catalogados por Silva (2000). Discriminação que chega a ser mais forte do que a sofrida pelos negros no Reino Unido (Lima, 2003). 
A teoria do racismo cordial ainda se encontra em fase de desenvolvimento, tendo alguns pesquisadores começado a analisar, no âmbito da psicologia social, os mecanismos históricos e psicossociais que subjazem a esta forma de racismo (e.g., Camino et al., 2001; França \& Monteiro, 2002).

\section{Considerações finais}

Não obstante as diferenças que existam entre as novas teorias sobre o racismo, comum a todas elas é a afirmação de que as novas expressões do racismo são disfarçadas e indiretas, e caracterizam-se pela intenção de não ferir a norma da igualdade e de não ameaçar o autoconceito de pessoa igualitária dos atores sociais. Não se quer significar com isto que as formas mais tradicionais e abertas de racismo, típicas das relações racializadas dos séculos XVIII, XIX e início do XX, deixaram de existir ou perderam em importância. Tencionamos apenas referir uma nova forma de expressão do racismo que procura conviver harmonicamente com a norma anti-racista, que, como uma erva daninha, nasce nas suas brechas. Também se deve referir que estas novas expressões de racismo, mais veladas e hipócritas, são tão ou mais danosas e nefastas do que as expressões mais abertas e flagrantes, uma vez que, por serem mais difíceis de ser identificadas, são também mais difíceis de ser combatidas.

Comum a todas estas atuais e mais veladas formas de expressão do racismo é também a sua capacidade de mutação ou transformação em expressões violentas. É como se o preconceito fosse um vírus latente ou adormecido, que corrói os tecidos sociais com violência discreta quando a norma da igualdade está saliente, mas que, quando encontra uma norma social qualquer que justifique a sua expressão mais virulenta, explode em fanatismo nacionalista e xenófobo. Paradigmáticos desta situação são os acontecimentos contra os marroquinos em El Ejido no sul da Espanha em fevereiro de 2000, contra os muçulmanos e árabes, em todo o mundo, depois dos atentados do dia 11 de setembro nos EUA, e também, ainda que em menor intensidade, contra os negros no Brasil depois que algumas universidades públicas implantaram um sistema de cotas para estudantes "negros" e "pardos".

A crítica mais substancial às novas teorias sobre o racismo parte de Bobo (1983). Bobo sinaliza dois pontos críticos na teoria do racismo simbólico. O primeiro, e menos importante, se refere ao nome. Para Bobo o racismo nada tem de simbólico, pois reflete conflitos reais de interesses entre brancos e negros e a discriminação concreta destes últimos. A segunda crítica parte de uma re-análise dos dados utilizados em dois estudos que compõem a teoria do racismo simbólico. Bobo (1983) verifica que a dimensão concreta ou real de conflito intergrupal e de percepção dos negros como uma ameaça econômica, por parte dos brancos, colocada em segundo plano pela teoria do racismo simbólico, é um bom preditor do racismo nos EUA. Bobo (1983) conclui afirmando que a teoria do racismo simbólico se equivoca quando considera que as reações subjetivas dos atores a eventos políticos e sociais está colocada estanque a uma dimensão de conflito real. Para
Bobo, pelo contrário, os brancos necessitam manter suas crenças, estereótipos e atitudes hostis contra os negros porque precisam justificar para eles próprios e para os outros a sua resistência às demandas de mudança social por parte dos negros.

Outra crítica que pode ser levantada se refere à "novidade" dessas "novas formas" de racismo. Os trabalhos de Allport, na década de 50 (Allport, 1954), e Kovel, no início dos anos 70 (Kovel, 1970/2001), demonstram que o preconceito e o racismo já naquela época haviam mudado sua forma de expressão, assumindo um caráter mais disfarçado e hipócrita. Neste sentido, talvez seja mais apropriado falar em novas teorias sobre o racismo do que propriamente em "novas formas" de racismo.

Existem ainda críticas mais específicas, a determinadas teorias sobre o racismo. Biernat et al. (1996), analisando a teoria do racismo aversivo, teoria que considera que o racismo surge de um conflito entre a necessidade de salvaguardar auto-imagem de pessoa igualitária e sentimentos negativos face aos negros, afirmam que esta teoria não apresenta nenhuma evidência empírica de que é a ameaça à auto-imagem de igualitário do participante que define o seu padrão ambivalente de atitudes. Além disso, tanto a teoria do racismo aversivo quanto a teoria do racismo ambivalente localizam como intrapsíquico o conflito que os indivíduos vivenciam entre valores igualitários e valores individualistas. Parece mais lógico supor que a vivência interna ou psicológica deste conflito reflete o próprio caráter conflitivo das democracias modernas, que simultaneamente salientam o valor da igualdade e o valor da competição (Billig, 1984).

A teoria do preconceito sutil de Pettigrew e Meertens (1995) (e aqui devemos referir que se trata de preconceito e não de racismo, diferentemente das outras teorias, porque o objeto de análise são crenças, avaliações e atitudes negativas relativamente a grupos minoritários, sem incluir diretamente os elementos de discriminação, de cerceamento de direitos ou de naturalização das diferenças que caracterizam o racismo) se baseia nos pressupostos de Rokeach (1960), sobre o papel da percepção de diferenças culturais como deflagrador da discriminação. Num certo sentido, esta teoria pode fazer supor que se os grupos minoritários se deixassem assimilar culturalmente ou se tornassem semelhantes aos grupos majoritários a discriminação contra eles acabava. No entanto, o papel da diferença no racismo nem sempre é linear ou direto, e parece decorrer muito mais da construção social da diferença do que da simples percepção (Amâncio, 1998), e também do tipo de diferença em causa e do tipo de grupo envolvido na comparação social.

Vala e colaboradores (Lima \& Vala, 2002; Vala, Brito, \& Lopes, 1999; Vala, Lopes, \& Brito, 1999; Vala, Lopes, Lima \& Brito, 2002) desenvolvem este argumento num conjunto de estudos e conseguem demonstrar primeiro que, como prediz o preconceito sutil, nas avaliações sobre os negros a percepção e o exagero das diferenças culturais desencadeia preconceito (Vala, Brito, \& Lopes, 1999). Todavia, noutro estudo, os autores verificam que quando estão em causa diferenças fundamentais na manutenção do estatuto dos grupos, são os 
negros percebidos como semelhantes os mais negativamente avaliados (Lima \& Vala, 2002).

No nosso entender, o cenário de teorias e pesquisas apresentados apontam para a necessidade de uma maior ênfase investigativa das novas expressões de preconceito e de racismo no âmbito da psicologia social brasileira, inclusive utilizando algo do arcabouço teórico e metodológico que estas novas teorias fornecem, a fim de encontrar elementos comuns e elementos particulares que assemelham e diferenciam o racismo e o preconceito no Brasil do racismo e do preconceito europeu e do norte-americano.

\section{Agradecimento}

Agradecemos os comentários e sugestões das professoras Isabel Correia e Dalila X. de França.

\section{Referências}

Allport, G. W. (1954). The nature of prejudice ( $3^{\underline{\underline{a}}}$ ed.). Wokingham: AddisonWesley.

Amâncio, L. B. Q. (1998). Masculino e feminino: a construção social da diferença $\left(2^{\mathrm{a}}\right.$ ed.). Porto: Afrontamentos.

Appiah, K. A. (1992). In my fathers' house: Africa in the philosophy of culture. Nova York: Oxford University Press.

Augoustinos, M., Ahrens, C., \& Innes, J. M. (1994). Stereotypes and prejudice: the Australian experience. British Journal of Social Psychology, 33, 125-141.

Bargh, J. A., Chen, M., \& Burrows, L. (1996). Automaticity of social behavior: direct effects of trait construct and social stereotype activation on action. Journal of Personality and Social Psychology, 71, 230-244.

Barker, M. (1981). The new racism. Londres: Junction Books.

Bastide, R., \& van den Berghe, P. (1957). Stereotypes, norms, and interracial behavior in São Paulo, Brazil. American Sociological Review, 22, 689-694.

Bell, D. W., \& Esses, V. M. (2002). Ambivalence and response amplification: A motivational perspective. Personality and Social Psychology Bulletin, 28, 1143-1152.

Ben Brika, J., Lemaine, G., \& Jackson, J. (1997). Racism and xenophobia in Europe. Bruxelas: European Commission.

Biernat, M., Vescio, T. K., Theno, S. A., \& Crandall, C. S. (1996). Values and prejudice: toward understanding the impact of American values on outgroup attitudes. In C. Seligman, J. M. Olson, \& M. P. Zanna (Orgs.), The Psychology of values: the Ontario Symposium (Vol. 8, pp. 153-189). Nova Jersey: Erlbaum.

Billig, M. (1984). Political ideology: social psychology aspects. In H. Tajfel (Org.), The social dimension: European studies in social psychology (Vol. 2., pp. 446-465). Londres: Cambridge University Press.

Bobo, L. (1983). Whites' opposition to bussing: symbolic racism or realistic group conflict? Journal of Personality and Social Psychology, 45, 1196-1210.

Brown, R. J. (1995). Prejudice: its social psychology. Oxford: Blackwell.

Camino, L., Silva, P., Machado, A., \& Pereira, C. (2001). A face oculta do racismo no Brasil: uma análise psicossociológica. Revista de Psicologia Política, 1, 13-36.

Cardoso, F. H., \& Ianni, O. (1959). Cor e mobilidade social em Florianópolis. São Paulo: Companhia Editora Nacional.

Conner, M., \& Sparks, P. (2002). Ambivalence and attitudes. European Review of Social Psychology, 12, 37-70.

Correia, I., Brito, R., Vala, J., \& Pérez, J. (2001). Normes antiracistes et persistance du racisme flagrant: analyse comparative des attitudes face aux Tziganes et face aux noirs au Portugal. Manuscrito não-publicado. Centro de Investigação e Intervenção Social/ISCTE.
Degler, C. N. (1971). Nem preto nem branco: escravidão e relações raciais no Brasil e nos EUA. Rio de Janeiro: Labor.

Dovidio, J. F. (2001). On the nature of contemporary prejudice: the third wave. Journal of Social Issues, 57, 829-849.

Dovidio, J. F., \& Gaertner, S. L. (1998). On the nature of contemporary prejudice: the causes, consequences, and challenges of aversive racism. In J. L. Eberhardt \& S. T. Fiske (Orgs.), Confronting racism: the problem and the response (pp. 3-32). Thousand Oaks, Califórnia: Sage.

Dovidio, J. F., \& Gaertner, S. L. (2000). Aversive racism in selection decisions: 1989 and 1999. Psychological Science, 11, 319-323.

Duckitt, J. (1992). A historical analysis and integrative framework. American Psychologist, 47, 1182-1193.

Essed, P. (1991). Understanding everyday racism. Londres: Sage.

França, D. X., \& Monteiro, M. B. (2002). Identidade racial e preferência em crianças brasileiras de 5 a 10 anos. Psicologia, 16(2), 293-323.

Gaertner, S. L. (1973). Helping behavior and discrimination among liberals and conservatives. Journal of Personality and Social Psychology, 25. 335-341.

Gaertner, S. L., \& Dovidio, J. F. (1986). The aversive form of racism. In J. F. Dovidio, \& S. L. Gaertner (Orgs.), Prejudice, discrimination, and racism (pp. 61-89). Orlando, Florida: Academic.

Guimarães, A. S. A. (1999). Racismo e anti-racismo no Brasil. São Paulo: Editora 34.

Jonas, K., Broemer, P., \& Diehl, M. (2000). Attitudinal ambivalence. European Review of Social Psychology, 11, 35-74.

Jones, J. M. (1972). Racismo e preconceito. São Paulo: Edgard Blücher.

Jost, J. T., \& Banaji, M. (1994). The role of stereotyping in system-justification and the production of false consciousness. British Journal of Social Psychology, 33, 1-27.

Katz, I., \& Hass, R. G. (1988). Racial ambivalence and American value conflict: correlational and priming studies of dual cognitive structures. Journal of Personality and Social Psychology, 55, 893-905.

Katz, I., Wackenhut, J., \& Hass, R.G. (1986). Racial ambivalence, value duality, and behavior. In J. F. Dovidio \& S. L. Gaertner (Orgs.), Prejudice, discrimination, and racism (pp. 35-59). Nova York: Academic.

Kinder, D. R., \& Sears, D. O. (1981). Prejudice and politics: symbolic racism versus racial threats to the good life. Journal of Personality and Social Psychology, 40, 414-431.

Kovel, J. (2001). White racism: a psychohistory. In E. Cashmore \& J. Jennings (Orgs.), Racism: essential readings (pp. 136-140). Londres: Sage. (Texto original publicado em 1970).

Lima, M. E. O. (2003). Normas sociais e racismo: efeitos do igualitarismo e do individualismo meritocrático na infra-humanização dos negros. Tese de Doutorado não-publicada. Instituto Superior de Ciências do Trabalho e da Empresa, Lisboa.

Lima, M. E. O., \& Vala, J. (2002). Individualismo meritocrático, diferenciação cultural e racismo. Análise Social, 37, 181-207.

McConahay, J. B. (1986). Modern racism, ambivalence, and the modern racism scale. In J. F. Dovidio \& S. L. Gaertner (Orgs.), Prejudice, discrimination, and racism (pp. 91-125). Nova York: Academic.

McConahay, J. B., \& Hough, J. C. Jr. (1976). Symbolic racism. Journal of Social Issues, 32, 23-45.

Myrdal, G. (1944). An American dilemma: the Negro problem and modern democracy. Nova York: Harper \& Row.

Pedersen, A., \& Walker, I. A. (1997). Prejudice against Australian aborigines: old-fashioned and modern forms. European Journal of Social Psychology, 27, 561-587.

Pereira, J. B. B., (1996). O retorno do racismo. In L. M. Schwarcz \& R. da S. Queiroz (Orgs.), Raça e diversidade (pp. 17-28). São Paulo: EDUSP.

Pettigrew, T. F. (1958). Personality and social-cultural factors in intergroup attitudes: a cross-national comparison. Journal of Conflict Resolution, 2, 29-42. 
Pettigrew, T. F. (1993). Regional differences in anti-negro prejudice. In E. Aronson \& A. R. Pratkanis (Orgs.), Social Psychology III (pp. 359-367). Brookfield: Edward Elgar. (Texto original publicado em 1959)

Pettigrew, T. F. (1985). New patterns of racism: the different worlds of 1984 and 1964. Rutgers Law Review, 1, 673-706.

Pettigrew, T. F., \& Meertens, R. W. (1995). Subtle and blatant prejudice in Western Europe. European Journal of Social Psychology, 25, 57-75.

Rokeach, M. (1960). The open and closed mind. Nova York: Basic Books.

Rousseau, J. J. (1989). Discurso sobre a origem e os fundamentos da desigualdade entre os homens. São Paulo: Ática. (Texto originalmente publicado em 1755)

Schwarcz, L. M. (1993). O espetáculo das raças: cientistas, instituições e a questão racial no Brasil. São Paulo: Companhia das Letras.

Schwarcz, L. M. (1996). As teorias raciais, uma construção histórica de finais do século XX. O contexto brasileiro. In L. M. Schwarcz \& R. da S. Queiroz (Orgs.), Raça e diversidade (pp. 147-185). São Paulo: EDUSP.

Sears, D. O. (1998). Racism and politics in the United States. In J. L. Ebrhardt \& S. T. Fiske (Orgs.), Confronting racism: the problem and the responses (pp. 76-100). Thousand Oaks Califórnia: Sage.

Sears, D. O., \& Kinder, D. R. (1971). Racial tensions and voting in Los Angeles. In W. Z. Hirsch (Org.), Los Angeles: viability and prospects for metropolitan leadership. Nova York: Praeger.

Sears, D. O., \& McConahay, J. B. (1973). The politics of violence: The new urban Blacks and the watts riots. Boston: Houghton Mifflin.

Silva, N. V. (2000). Extensão e natureza das desigualdades raciais no Brasil. In A. S. A. Guimarães \& L. Huntley (Orgs.), Tirando a máscara: ensaios sobre racismo no Brasil (pp. 33-52). São Paulo: Paz e Terra.

Skidmore, T. (1993). Bi-racial U.S.A. vs. multi-racial Brazil: is the contrast still valid? Journal of Latin American Studies, 25, 376-386.
Snowden Jr., F. M. (1983). Before color prejudice: the ancient view of Blacks. Cambridge, Massachusetts: Harvard University Press.

Snowden Jr., F. M. (1995). Europe's oldest chapter in the history of black-white relations. In B. P. Bowser (Org.), Racism and anti-racism in world perspective (pp. 3-26). Londres: Sage.

Stephan, W. G. (1985). Intergroup relations. In G. Lindzey \& E. Aronson (Orgs.), Handbook of Social Psychology (3 ${ }^{\mathrm{a}}$ ed., Vol. 2, pp. 599-658). Nova York: Random House.

Tajfel, H. (1981). Human groups and social categories: studies in social psychology. Cambridge: Cambridge University Press.

Turra, C., \& Venturi, G. (1995). Racismo cordial: a mais completa análise sobre preconceito de cor no Brasil. São Paulo: Ática.

Vala, J., Brito, R., \& Lopes, D. (1999). Expressões dos racismos em Portugal: perspectivas psicossociológicas. Lisboa: Editora do Instituto de Ciências Sociais da Universidade de Lisboa.

Vala, J., Lopes, D., \& Brito, R. (1999). A construção social da diferença: racialização e etnicização das minorias. In J. Vala (Org.), Novos racismos: perspectivas comparativas (pp. 145-179). Oeiras: Celta.

Vala, J., Lopes, D., Lima, M. E. O., \& Brito, R. (2002). Cultural differences and hetero-ethnicization in Portugal: the perceptions of black and white people. Portuguese Journal of Social Sciences, 1(2), 111-128.

Walker, I. (1994). Attitudes toward minorities: survey evidence of the Western Australians attitudes to Aborigines, Asians and women. Australian Journal of Psychology, 46, 41-56.

Walker, I. (2001). The changing nature of racism: from old to new? In M. Augoustinos \& K. J. Reynolds (Orgs.), Understanding prejudice, racism, and social conflict (pp. 24-42). Londres: Sage.

\section{Notas}

1 Este trabalho é uma versão de um dos capítulos da Tese de Doutorado do primeiro autor, sob a orientação do Prof. Jorge Vala, defendida em 31 de Janeiro de 2003, no Instituto Superior de Ciências do Trabalho e da Empresa (Portugal).

2 Extraído da obra Discurso sobre a origem e os fundamentos da desigualdade entre os homens, de J. J. Rousseau (1989/1755).

3 An aversive or hostile attitude toward a person who belongs to a group, simply because he belongs to that group, and is therefore presumed to have the objectionable qualities ascribed to the group. (Allport, 1954, p. 7)

4 Ethnic prejudice is an antipathy based upon a faulty and inflexible generalization. It may be felt or expressed. It may be directed toward a group as a whole, or toward an individual because he is a member of that group. (Allport, 1954, p. 9)

5 "Derrotado intelectualmente, o preconceito resiste emocionalmente"

6 Neste trabalho, seguindo Appiah (1992), utilizaremos os termos "relações racializadas" ou "grupos racializados" ao invés dos termos "relações raciais" ou "grupos raciais", para referir o processo de essencialização e naturalização (racialização) de que são alvo os grupos definidos por alguma marca física externa, real (e.g., a cor da pele dos negros) ou imaginada (e.g., o nariz aquilino dos judeus).

7 Cabe referir que Martin Barker (1981) publicou na década de 1980 um livro intitulado The new racism, no qual denuncia a emergência de uma nova forma de racismo, baseado nas idéias da diferenciação cultural e da percepção de que os imigrantes ameaçam a cultura dominante.

8 Credo (ou crença) americano.

9 Consequently, the nation that pushed the idea of freedom and equality to the highest point yet attained was also the nation that pulled the idea of degradation and dehumanization to the lowest level ever sounded, to pure nothingness. (Kovel, 1970/2001, p. 139)

10 Sentimento considerado positivo por Katz e Hass (1988). 
11 Priming é um procedimento metodológico que ativa estruturas de conhecimento, tais como estereótipos e crenças, que influenciam avaliações e comportamentos subsequentes. Em outros termos, trata-se da produção de um contexto que influencia determinadas respostas não diretamente relacionadas com este contexto (Bargh, Chen \& Burrows, 1996).

12 hot, close and direct. (Pettigrew \& Meertens, 1995, p. 58)

13 Nome do grupo minoritário

14 O Eurobarômetro compreende uma ampla pesquisa anual e temática realizada junto a amostras representativas de vários países europeus.

15 Uma ampla pesquisa realizada na década de 1970 pelo IBGE, com amostra representativa da população brasileira, verificou que os brasileiros, quando são solicitados a se auto-definirem em termos de cor da pele, apresentam 135 classificações de cor diferenciadas (ver Turra \& Venturi, 1995).

Marcus Eugênio Oliveira Lima, doutor em Psicologia Social pelo Instituto Superior de Ciências do Trabalho e da Empresa, ISCTE, Lisboa, Portugal, é professor no Departamento de Psicologia da Universidade Federal de Sergipe. Endereço para correspondência: Rua Atalaia, 260, ap. 103; Aracaju, SE; CEP 49035-110. Fax: (79) 212-6755.E-mail: meolima@uol.com.br

Jorge Vala, doutor em Psicologia Social pela Université Catholique de Louvain (Bélgica), é professor no Instituto Superior de Ciências do Trabalho e da Empresa, Universidade de Lisboa. 